\title{
Barriers to Incident Reporting among Nurses: A Qualitative Systematic Review
}

Moataz Mohamed Maamoun Hamed, MSc, Stathis Th Konstantinidis*, PhD, MSc

School of Health Sciences, University of Nottingham, UK

Moataz Mohamed Maamoun Hamed, Quality Coordinator, ORCiD: 0000-0002-6460-5098

Stathis Konstantinidis, Associate Professor in e-learning and Health Informatics, ORCiD: 0000-0002-3680-4559

*Corresponding author: Stathis Th Konstantinidis, QMC, B floor School of Health Sciences, University of Nottingham, NG7 2HA, UK, phone: +44 (0) 11582 30481, email: Stathis.Konstantinidis@nottingham.ac.uk

\section{Disclosure of interest}

The authors report no conflict of interest. 


\title{
Barriers to Incident Reporting among Nurses: A Qualitative Systematic Review
}

\begin{abstract}
Incident reporting in healthcare prevents error recurrence, ultimately improving patient safety. A qualitative systematic review conducted, aiming to identify barriers to incident reporting among nurses. Joanna Briggs Institute methodology for qualitative systematic reviews followed, data extracted using JBI QARI tools and selected studies assessed for methodological quality using CASP. A meta-aggregation synthesis was carried out, and confidence in findings was assessed using GRADE ConQual. 921 records identified, but only five studies included. The overall methodological quality of these studies was good and GRADE ConQual assessment score was 'moderate'. Fear of negative consequences was the most cited barrier to nursing incident reporting. Barriers also included inadequate incident reporting systems and lack of interdisciplinary and interdepartmental cooperation. Lack of nurses' necessary training made it more difficult to understand the importance of incident reporting and the definition of error. Lack of effective feedback and motivation and a pervasive blame culture also identified.
\end{abstract}

Key Words: Near miss errors; medication errors; sentinel events; patient safety 
The World Health Organization defines an incident as "any deviation from the usual care that poses a risk of harm or causes injury to a patient, it includes errors, preventable adverse events, and hazards" (World Health Organization [WHO], 2005), These errors are one of the main persistent threats to patient safety (Bifftu et al., 2016; Chard, 2006). As shown in the Institute of Medicine (IOM) report 'To Err is human', hundreds of people die every day due to preventable medical errors, which is much more than people who die because of airplane accidents (Institute of Medicine (US) Committee on Quality of Health Care in America, 2000). Economic losses of health care organizations are also a result of medical and nursing errors, more than 15 per cent of health spending is wasted on costs of additional hospitalization, litigations, and other consequences of adverse events and poor quality (World Health Organization [WHO], 2018).

All professionals are bound to make mistakes from time to time, especially in a complex profession as health care (Cleary et al., 2018), but a key step in improving the quality of care and enhancing the patients' safety is learning from these mistakes (Ellis \& Abbott, 2019). One of the main ways of monitoring errors to prevent their recurrence is incident reporting (Hwang et al., 2012). An incident reporting system (IRS) is one of the bases of safe practice within an organization, having an effective incident reporting system in the organization significantly increases the safety of the patients (Pham et al., 2010), it enables the organization to learn from past errors (Stavropoulou et al., 2015), and also helps identify potential risk and alert staff to possible system failures in the organization (Pham et al., 2010).

In health care, 'Silence Kills' (Ackerman, 2018; Wolf \& Hughes, 2008), thus, both obligatory and voluntary reporting in hospitals are encouraged. While a well-reported, analyzed, and openly communicated incident helps everyone in the workplace understand the circumstances in which that incident occurred, learn from it, and thus preventing similar errors 
from occurring in the future (Galt \& Paschal, 2009), nurses are reluctant to report medication errors, while they can identify them (Dirik et al., 2019).

Even though it has its drawbacks, incident reporting remains one of the most widespread strategies to improve patient safety (Macrae, 2016). Reporting is not just about speaking up, transparency about errors, or openness in communication, nor is it about filling up a form; it is about taking the first step in fixing a problem at hand and learning from it to avoid its recurrences, and voluntary reporting can really help identify healthcare systems' vulnerabilities (Vincent, 2011). Reporting of events is of little value unless the data reported were appropriately analyzed by skillful personnel (Wallace, 2010).

So it is pivotal that organizations stress on what comes after incident reporting, but first, patient safety incidents must be clearly defined and prioritized in order to deal with them according to their risk (Wolf \& Hughes, 2008). Incidents can be classified into adverse events which implies an unintended injury that is resulted from medical management, mistakes/errors which are acts of commission or omission, near-misses which are errors without a subsequent adverse event, and bad outcomes which are undesirable outcomes due to a disease process (WHO, 2005). Reporting in the context of this paper includes both self-reported errors as well as errors reported by other healthcare professionals, but not errors reported by automated software systems.

Organizations that have characteristics of transparency, openness in communication and learning from their mistakes, tend to be much safer and more successful than those who do not (Reason, 2016). In a time where continuous quality improvement is essential for any organization to excel, every error that occurs -no matter how small or big it is- should be considered as an opportunity to improve. Incident reporting also helps organizations identify if there is a need for a process change or a system reform (Wolf \& Hughes, 2008). 
Potential future medical errors can best be prevented through reporting near misses (Wolf \& Hughes, 2008). The reporting and analysis of near-misses as well as errors can promote a 'culture of learning' in health care organizations, creating an opportunity for all health care professionals to learn and prevent errors from happening (Galt \& Paschal, 2009). A 'restorative' justice approach is better than a 'retributive' justice approach in that a restorative approach works towards understanding failure and fixing it rather than only focusing on the individuals involved. An organization with a 'just culture' should not only look at the sharp end of the organization where frontline staff work and most accidents happen, instead, they should dig deeper, hear from everyone, relate and express remorse. There should be a less sense of blame, and a more shared sense of trust, learning, and also accountability (Dekker, 2018), allowing people to be more engaged and become part of the solution instead of fearing for their careers. This is all considered a part of the road towards making healthcare establishments high-reliability organizations (Sutcliffe et al., 2017).

There should be a process of justly engaging, listening to, and crying with the people involved in errors, 'holding people accountable' does not always have to mean sanctions and punishment (Dekker \& Hugh, 2014). Humans are fallible, and thus errors are inevitable, but working together to understand the complex high-risk system that healthcare workers work within shall lead to a prevalence of a 'culture of learning' and understanding why these errors happen and thus preventing them from happening in the first place (Israelski, 2010). Hospitals should always work towards design-driven improvement to help 'design-out' potential mistakes (Fondahn et al., 2016), and helping staff identify challenges in their work without assuming it is their fault. The focus should be on the system, to find out latent errors (Reason, 2000) and understand the resilience involved.

Health care regulatory bodies and oversight entities have recently started mandating that health care organizations submit certain reports concerning adverse events, however, 
without institutionally-based voluntary incident reporting, it is very difficult and challenging to catch errors (Wachter, 2012).

One in 10 hospitalized patient experiences an adverse event during their stay (Michel et al., 2017). Studies show that a great number of errors are made by nurses (Thomas, 2010), as 30 per cent of nurses admit to committing at least one error every month (Hashemi, 2008), while nurses is less likely to report a medication error, especially near misses (Farag et al., 2017; Lee, 2018). The underreporting of adverse events and near-mises remains high despite multiple reporting systems (Hamilton et al., 2018). Underreporting is considered a significant challenge facing error monitoring and error reduction efforts (Noble \& Pronovost, 2010).

In order to start developing interventions that would encourage error reporting among nurses and increase their willingness to report, we first need to identify the barriers to nursing error reporting. A number of studies conducted over the past 20 years in efforts to identify the factors contributing to error reporting by nurses and other health care professionals. Barriers identified include the lack of effective feedback to the reporter (Evans et al., 2006), as well as many other organizational and individual factors like the perceived negative administrative reactions and the culture of blame (Aboshaiqah, 2013). Systematic evidence explored attitudes or perceived barriers towards incident reporting of nurses' mainly working in an acute care settings (Fung et al., 2012a), identifying that "incident reporting vary across different study settings, with perceived barriers hindering the reporting process", thus any potential intervention should be adapted to the different setting in order to increase reporting rates. Furthermore, (Vrbnjak et al., 2016) systematically reviewed the literature until 2015 to identify barriers to nurses' reporting of medication errors and near misses, identifying that a "a nonblaming, non-punitive and non-fearful learning culture at unit and organizational level" is needed in order to enhance the reporting rates of medication errors and near misses. Efficiency of the reporting systems, management behavior, and nurses' education were the main areas 
where barriers identified, while Rohde and Domm (2018) concluded that there is "minimal evidence clearly articulating nurses' clinical reasoning used to support medication errors".

Considering the fact that underreporting of errors in healthcare is still common in many countries including the UK, USA, China (Gao et al., 2019), and South Korea (Lee, 2017), and barriers on incident reporting is a continuous evolving field of research, there is a need to further synthesize existing evidence on barriers on incident reporting not only on medication errors, as it has clear implications on patient safety, health care research and health care policy. Although findings of quantitative, qualitative and mixed method studies on barriers to nursing incident reporting appear to be somewhat similar, this review critically assessed the most relevant qualitative studies individually, synthesizing their findings to present a synthesized summary of the most important findings and conclusions, degerming the meaning of the phenomenon. The review contributes to nursing practice as it identifies the main barriers to nurses reporting, researchers and policy makers can use these findings to develop strategies to encourage and increase reporting, leading to a more effective error reporting systems in health care.

\section{Methods}

A qualitative systematic review approach followed, using the Joanna Briggs Institute (JBI) methodology for qualitative systematic reviews (Pearson et al., 2005; The Joanna Briggs Institute, 2014). The research question was framed using the PICoS (Population / Participants, Phenomenon of Interest, Context / Setting, Study Design) framework (Methley et al., 2014).

\section{Search Strategy}

A scoping pilot search on PubMed and CINAHL databases was conducted, so as to get a broad picture of the available literature and identify the most appropriate keywords (Tong et al., 2012). Following the initial search, the search queries were carefully tested and fine-tuned, 
using alternative terminology and synonyms that could be used to give more appropriate results by both authors. The multi-field search query was: (nurs* OR midwi*) AND (barrier* OR obstacle* OR hind*) AND (report* OR statement* OR claim*) AND (error* OR Incident* OR event* OR near miss* OR near-miss* OR fault* OR mistake* OR mishap ${ }^{*}$ ) AND (qualitative OR interview* OR field stud* OR narrative* OR experience* OR opinion* OR view* OR perception * OR outlook* OR belief* or emotion* OR focus group $*$ OR attitude $*$ ). A systematic search was conducted in five healthcare related bibliographic electronic databases: PubMed, CINAHL, HMIC, PsycINFO and EMBASE. All the identified papers were imported to 'Mendeley' reference management system and duplicates were removed. The PRISMA (Preferred Reporting Items for Systematic Reviews and Meta-Analyses) tool was utilized to undertake the studies' selection process. After the duplicates were removed, titles and abstracts of the remaining papers were read and examined against the eligibility criteria, then a thorough screening of the full paper was done to identify studies that exactly match the set review criteria (Moher et al., 2009).

\section{Inclusion and Exclusion Criteria}

\section{Types of Participants}

Only studies where the participants were nurses considered for inclusion in this review, studies that explore the views of patients or health care professionals other than nurses were excluded. The choice to limit the review to the nurses' perceptions was made because nurses have a very significant role to play in the error reporting systems (Wolf \& Hughes, 2008). There were no limitations on the roles/type of nurses, so studies that had participants from emergency care, acute care, ambulatory care, home care, hospice care, long term care, or psychiatric health care were all considered.

\section{Phenomena of Interest}


There were no limitations on the type of the reporting incident, so barriers to reporting near misses, medication errors, and sentinel events were all considered. Studies that addressed both barriers and facilitators to nursing incident reporting were also considered.

\section{Context}

The review included nurses working in any health care facility (e.g. primary, secondary, or tertiary) and in any country. All studies that were undertaken before the year 2000 were excluded, considering the fact that it was not until that year that patient safety and quality of care started to become a big part of health care research (Leape \& Berwick, 2005; Stelfox et al., 2006). While multiple studies exist before 2000, the landmark IOM report recommended reforms that would expand reporting substantially (Leape, 2002) and many countries, such as the UK, Denmark, and Australia developed a national incident reporting system, while 15 years later, error reporting has not yet reached its full potential (Mitchell et al., 2016). Only studies published in English were included.

\section{Type of Studies}

This systematic review focused on qualitative studies that report beliefs, opinions, attitudes, and experiences, through interactive data collection methods like interviews and focus group discussion. All quantitative and mixed method studies were excluded. While the qualitative part of mixed methods studies, when clearly presented, have been included in qualitative systematic reviews the value of mixed methods studies' findings is in the combination of data and explored separately without taking into considerations the types of mixed methods designs (e.g. explanatory, exploratory, parallel, nested (embedded) designs (Shorten \& Smith, 2017)) might engage some bias. Qualitative studies make distinctive contributions to leadership studies (Bryman et al., 1996) and are much more appropriate and effective when studying perceptions and experiences (Parse et al., 1985; Pope \& Mays, 2006) and hospitals have the best chance of tackling barriers that hinder reporting by using 
questionnaires for nurses to identify these barriers, then work to encourage better reporting (Rutledge et al., 2018). Only studies published in peer-reviewed journals were considered. Systematic reviews, editorials, notes, commentary pieces, conference papers, book chapters, theses, were excluded.

\section{Assessment of Methodological Quality}

All included papers assessed for methodological validity. To determine the methodological quality of the paper, the Critical Appraisal Skills Program (CASP) tool for qualitative studies was used (No Author, 2018). There was no weight to specific questions nor was there a scoring system for the checklist, however, each answer was explained and justified. There were no exclusions made based on the methodological quality of the studies, but they contribute to the interpretation of the overall findings (Dixon-Woods et al., 2004).

\section{Data Extraction}

The standardized qualitative data extraction tool "QARI" (Qualitative Assessment and Review Instrument) (The Joanna Briggs Institute, 2014) used to extract the data from the included papers. The process of data extraction in a meta aggregation approach is a multi-phase process, as the JBI QARI tool includes two forms, the first one is where the general details of the study were extracted, including but not limited to; citation details, phenomenon of interest, participants, setting, geographical and cultural information, study methods, and conclusions. The second part of data extraction using JBI QARI (which is also considered the first step in data synthesis) is where the findings that are relevant to the review question were extracted. 'Findings' are the statements and texts of interest to the review as published in primary studies. The included papers were read more than once until a good understanding of the studies, their context, and their outcome was gained. The findings which were reported in the papers as 'categories' were extracted to the QARI form and accompanied by a verbatim illustration from the publication, this illustration was either a direct quotation from a study participant, or where 
not available, other supporting data from the author's words (The Joanna Briggs Institute, 2014). A level of credibility based on the degree of evidence of the illustration was assigned in each finding. The first author extracted the data, while the second author agreed the extracted data.

\section{Data Synthesis}

The JBI meta aggregation approach (The Joanna Briggs Institute, 2014) used for data synthesis. In the process of meta aggregation, there is no re-interpretation of the studies' findings or the generation of new outcomes, instead, the meta aggregation approach aims at organizing evidence, by compiling categories articulated by the researchers of the primary studies, and creating synthesized findings that helps avoid misunderstandings and misinterpretations (Florczak, 2019). The process of meta aggregation is an explicit interpretive process that involves the extraction of studies' findings, then processes of categorization and synthesis (Hannes \& Lockwood, 2011).

Every two or more related study findings were grouped together into 'categories'. They were grouped on the basis of similarity in meaning and concept, and only the credible $(\mathrm{C})$ or unequivocal $(\mathrm{U})$ findings were included in the categorizing process. These categories were then compared and synthesized to generate overarching synthesized findings (a set of statements that represent the best aggregation of categories and findings). Authors re-examined each finding to make sure the process was done exhaustively, and descriptions were developed for each category and synthesized finding of the review (Hannes \& Lockwood, 2011).

\section{Assessment of Confidence in Review Findings}

Establishing confidence in the synthesized findings was done using the GRADE ConQual tool (Munn et al., 2014), where the included papers were graded and a ranking system was utilized to determine the extent to which the findings were a reasonable representation of the phenomenon of interest. This was done through the assessment of dependability (i.e. 
reliability) by answering a set of questions related to the quality and the appropriateness of the papers, and credibility (i.e. internal validity) which was assessed according to the authors' view of how well the review findings fit with data from the original studies (Munn et al., 2014).

\section{Study Inclusion}

\section{Results}

A total of 921 records were identified (235 from PubMed, 183 from CINAHL, 28 from HMIC, 87 from PsycInfo, and 388 from EMBASE) and 422 duplicates removed. Titles and abstracts of the remainder 499 papers reviewed by first author. 12 studies included for full-text assessment for eligibility, resulting to five studies selected independently by both authors meeting the inclusion and exclusion criteria, as depicted in the PRISMA (Preferred Reporting Items for Systematic Reviews and Meta-Analyses) flowchart (Figure 1) (Moher et al., 2009). The seven studies excluded for the following reasons: explored physicians' and not nurses' perceptions, while this systematic review only focuses on nurses' perceptions; use of a quantitative questionnaire approach, while this systematic review only focuses on qualitative studies; one study was a thesis and not a published, peer-reviewed article; for one study only the abstract was available as it was part of conference proceedings; for one study only the abstract was available in English.

\section{Assessment of Methodological Quality}

The quality of each study was assessed through the utilization of the CASP qualitative checklist. All five studies included clear descriptions of how they were conducted as a whole. The overall quality of the included studies can be considered relatively good, however, all the included studies failed to clearly address the researchers' relationships with the participants. Potential bias and the risk of influence of the researcher should have been discussed to allow for more reflexivity in the studies (Malterud, 2001). In relation to sampling, one of the five studies did not mention its recruitment strategy at all (Hashemi et al., 2012), and two of the 
five studies did not discuss data saturation (Hwang et al., 2012; Peyrovi et al., 2016). Table 1 depicts a summary of the overall methodological quality of the included studies.

\section{Study Characteristics}

All the five included studies were published within the past eight years (from 2012 to 2019). Coincidently, all five studies were conducted in developing Asian countries, two studies in Iran (Hashemi et al., 2012; Peyrovi et al., 2016), one in Korea (Hwang et al., 2012), one in Malaysia (Dyab et al., 2018), and one in China (Song \& Guo, 2019). Four of the five studies were conducted in urban settings (Dyab et al., 2018; Hashemi et al., 2012; Peyrovi et al., 2016; Song \& Guo, 2019), while one study did not mention specific locations (Hwang et al., 2012).

All participants in the five studies were nurses, in different age groups and with varying years of working experiences. A total of 234 nurses were included in these five studies, the majority of which were female nurses, the exact female to male ratio is not available because one of the five studies did not mention the numbers of male and female nurses (Hashemi et al., 2012). Three studies included nurses working in different hospital wards and hospital clinics (Dyab et al., 2018; Hashemi et al., 2012; Hwang et al., 2012), one study included nurses working only in the intensive care units of hospitals (Peyrovi et al., 2016), and one study included nursing interns only (Song \& Guo, 2019).

In relation to sampling, two studies used a convenience and purposive sampling technique (Peyrovi et al., 2016; Song \& Guo, 2019), one study used snowball sampling (Hwang et al., 2012), one used both convenience and snowball sampling techniques (Dyab et al., 2018), and one study did not identify the sampling method used (Hashemi et al., 2012). All studies underwent ethical approval as well as got written consents to participate from the nurses.

Two studies used focus group discussions to collect data from the participants (Hashemi et al., 2012; Song \& Guo, 2019), two studies used in-depth semi-structured face-to-face interviews with the nurses to collect the data (Dyab et al., 2018; Peyrovi et al., 2016), and one 
study used a methodological triangulation where they used face-to-face interviews as well as emails to collect the data (Hwang et al., 2012). Four of the five studies conducted the interviews and focus group meetings in English (Hashemi et al., 2012; Hwang et al., 2012; Peyrovi et al., 2016; Song \& Guo, 2019), while one study had a couple of interviews conducted in Malay (the native language of the participants) for nurses who could not express their thoughts in English, but translators worked closely with the researchers to get the nurses' exact views (Dyab et al., 2018) (Table 2).

\section{Findings of the Review}

A total of 56 findings were extracted, 13 of them were not included in the synthesis process as their credibility level was 'unsupported'. The remaining 43 findings were either unequivocal or credible. These 43 findings were aggregated into eight categories, and these categories were aggregated into four overarching synthesized findings (Table 3).

\section{Synthesized Finding 1: There is a fear among nurses of the negative consequences of reporting, arising from their co-workers and supervisors}

Three out of the five included studies (Dyab et al., 2018; Hashemi et al., 2012; Peyrovi et al., 2016) identified "fear of the repercussions of incident reporting" as a major theme because nurses usually mention it as the main barrier, whether that fear was fear of being stigmatized by their co-workers and supervisors, or fear of an inadequate response by the management in the form of a severe disciplinary action.

One of the main reasons nurses do not feel encouraged to report any patient safety incident is because they are afraid they would get sued and face legal problems (Dyab et al., 2018; Peyrovi et al., 2016), and lose a lot of money (Hashemi et al., 2012). Another reason nurses underreport is the fear of being stigmatized for a long time by their co-workers (Peyrovi et al., 2016); 
Nurses are also concerned about the management reactions, negative reactions to error reporting from supervisors are common as supervisors tend to blame and punish the nurses instead of offering support and working with them to reach the root causes of the error.

\section{Synthesized Finding 2: There is a lack of the organizational support needed to foster an incident reporting milieu for nurses}

The organization should be committed to supporting nurses by all means, including developing an effective reporting system. Most studies showed that the incident reporting system in the organization does not encourage nursing error reporting (Dyab et al., 2018; Hwang et al., 2012; Peyrovi et al., 2016; Song \& Guo, 2019), they discussed the inconvenience of the error reporting processes as one of the barriers, as well as the lack of confidentiality and anonymity in reporting (Dyab et al., 2018).

Also in relation to the inadequacy of the reporting system, nurses from more than one study mentioned lack of time and heavy workload are reasons some errors go unreported (Dyab et al., 2018; Hashemi et al., 2012).

\section{Synthesized Finding 3: Some nurses are not well trained to take part in the incident reporting system}

Most of the included studies evidenced a lack in the skills, knowledge and training required to take part in effective incident reporting (Hashemi et al., 2012; Hwang et al., 2012; Song \& Guo, 2019). Lack of cooperation was identified as one of this finding's categories, however, only two out of the five included studies supported that category (Hwang et al., 2012; Song \& Guo, 2019). Furthermore, some nurses believe that the definition of error is vague, or the outcome of an error define the need of reporting (Hashemi et al., 2012; Hwang et al., 2012).

\section{Synthesized Finding 4: Nurses lack the motivation and commitment needed to ensure their active participation in the incident reporting system}

Studies showed that some nurses are unwilling to accept the responsibility of an error as they do not have a reason to be committed to their work. (Hashemi, 2008; Peyrovi et al., 2016). On the individual level, nurses choose not to report their errors for different personal 
reasons. The feeling of shame, dishonor, and embarrassment are some common barriers (Dyab et al., 2018; Song \& Guo, 2019). Nurses feel that committing n reporting an error might result to stigmatizing (Song \& Guo, 2019).

\section{Assessment of Confidence in Review Findings}

Confidence in the results were also evidenced using the GRADE ConQual tool (Munn et al., 2014). The JBI ranking scheme (The Joanna Briggs Institute, 2014) was established and review findings were scored and assessed according to it. Table 4 depicts the ConQual assessment results as well as a summary of the review findings.

\section{Discussion}

Existing systematic evidence on barriers to reporting of medication errors and nearmisses highlighted the need for further research on the topic (Vrbnjak et al., 2016), while an earlier systematic review on barriers to incident reporting among nurses was limited to nurses working in acute care settings only (Fung et al., 2012b). This review takes a more diverse approach in terms of both clinical settings and the types of incidents, aiming to capture generic and recurring safety issues (Holmström et al., 2012).

There seems to be an abundance in evidence supporting the findings of this review. Fear of negative consequences was the most supported barrier identified in this review, as it was the most frequently described and the strongest perceived barrier in thirteen different studies that were done to address the issue of barriers to incident reporting (Chiang et al., 2010; Chiang, 2005; Copping, 2005; Fathi et al., 2017; Fernandez et al., 2010; Kingston, 2011; Lin \& Ma, 2009; Mansouri et al., 2019; Mayo \& Duncan, 2004; Petrova, 2010; Qin et al., 2015; Yumei et al., 2016; Yung et al., 2016).

These negative consequences included unpleasant reactions from co-workers (Fernandez et al., 2010), supervisors (Mayo \& Duncan, 2004), and administrations (H. Chiang, 
2005). These feared unpleasant reactions included but were not limited to: blame (Mansouri et al., 2019; Maurer, 2010), reprimand (Qin et al., 2015), punishment (Fathi et al., 2017), and being stigmatized (Mansouri et al., 2019).

The review identified that managerial misconduct is also a barrier to incident reporting among nurses, as previous poor reactions to errors from the organization lead to a decrease in nursing reporting. Organizations that adapts a 'culture of blame' are more likely to have low reporting rates (Almutary \& Lewis, 2012; Hesari et al., 2015; Kingston, 2011; Mansouri et al., 2019). Kingston (2011) and Mansouri et al. (2019) identified "the existence of a culture of blame" as a barrier to error reporting among nurses, Hesari et al. (2015) identified that authorities tend to focus on the person who made the error and not how to learn from it, which discourages nurses from reporting.

Lack of the appropriate support from the organization to the nurses who report their errors was another barriers identified in this review, which is similar to the main findings of six other studies (Azadi et al., 2011; Elder et al., 2008; Evans et al., 2006; Handler et al., 2007; Mostafaei et al., 2014; Sanghera et al., 2007). Lack of effective feedback was identified as a main barrier in multiple studies (Evans et al., 2006; Mostafaei et al., 2014), nurses felt it was futile to report (Brubacher et al., 2011) as there was no follow up investigations (Azadi et al., 2011).

In terms of the incident reporting system of the organization, in many studies (Brubacher et al., 2011; Elder et al., 2008; Fathi et al., 2017; Fernandez et al., 2010; Kingston, 2011; Mostafaei et al., 2014; Moumtzoglou, 2010) nurses mentioned the difficulties in the incident reporting process as a major barrier to reporting, which confirms the review's findings. A difficult reporting process (Kingston, 2011) that does not respects the nurses' heavy workload (Fernandez et al., 2010; Moumtzoglou, 2010) and time constraint (Brubacher et al., 2011; Elder et al., 2008) is what makes nurses not report. Other inconveniences in the incidents 
reporting system (such as the lack of confidentiality) were also considered among the barriers to nursing error reporting (Grant \& Larsen, 2007; Jeffe et al., 2004).

This review found that error underreporting among nurses can simply be a response to the lack of the appropriate nurses' training required to implement an effective reporting system. Many studies argue that the reason nurses do not report their errors is the absence of adequate education about the reporting process, some nurses do not know what exactly constitutes an error (Fathi et al., 2017), Mostafaei et al. (2014) identified "lack of clear definition of what to report" as a barrier to nurses' reporting. The following seven studies attributed error underreporting among nurses to barriers like the ambiguity of the notion of error and lack of nurses' knowledge and skills related to incident reporting (Brubacher et al., 2011; Fathi et al., 2017; Hesari et al., 2015; Kreckler et al., 2009; Mansouri et al., 2019; Mostafaei et al., 2014; Wakefield et al., 1996).

Nursing administration, organizational leaders and other relevant stakeholders should try to develop an atmosphere where nurses report their errors honestly and without fear, while providing them with the necessary training and educational programs on patient safety and incident reporting, and giving them feedback while investigating the systems' errors rather than blaming the individuals. A thorough review was undertaken to help develop an effective form of feedback to the reporting of safety issues in healthcare (Benn et al., 2009), identifying different modes of incident reporting feedback. The Safety Action and Information Feedback from Incident Report (SAIFIR) framework identified that effective feedback relies on timely corrective actions, and broad dissemination of information among other things such as appropriateness of feedback delivery and frontlines empowerment (Benn et al., 2009).

The background section mentioned the rationale for undertaking this review, which included clear evidence based implications for the quality and patient safety improvement science and research, the fundamental purpose of reporting errors is to learn how to improve 
(Firth-Cozens, 2002), and so, identifying and facing the barriers to reporting shall help create an organization where error reporting is culturally acceptable, ultimately leading to improving the safety of both the patients and the staff (Pham et al., 2010). A "just culture" (Marx, 2005) that minimizes punishments and have the right balance of safety and accountability could help achieve this (S. Dekker, 2016b). A significant amount of resources should be allocated by leadership to intensively analyze these errors, and apply the lessons derived from error reporting to the healthcare system.

An effective incident reporting system should include all type of incidence; near misses, at-risk behaviors, hazardous conditions, and other types of adverse events. Learning should be communicated throughout the organization and the healthcare industry (Galt \& Paschal, 2009), and every relevant stakeholder and health professionals (physicians, nurses, and allied healthcare professionals) should be involved in the process of reporting. An incident reporting system is usually successful when it is voluntary, non-punitive, and protected, this type of working environment allows innovation and learning to flourish (S. Dekker, 2016a). The process of reporting is of vast importance in health care, because when frontline staff report any type of error that took place in their department, this helps the organization understand what is going wrong, and therefore work on preventing the recurrence of this error in any other department, and ultimately helping improve the patients' outcomes (S. Dekker, 2018).

Many healthcare accrediting organizations -such as The Joint Commission (International \& Organizations, 2007)-, regulatory bodies, and other healthcare oversight entities -such as the Patient Safety Organizations (Elkin et al., 2016)- have recently started mandating that health care organizations submit certain reports concerning adverse events that happens in the hospital, along with the analysis performed to reach the root cause of that event and the action taken to prevent its recurrence. However, without institutionally-based voluntary incident reporting, it is very difficult and challenging to catch and learn from all errors 
(Wachter, 2012). Many hospitals have started working on quality improvement projects and other strategies that aim to increase the 'patient safety culture' and reporting in the hospitals (Gleeson et al., 2019; Parmelli et al., 2012)

A complete meta-aggregation schematic / overview flowchart was developed, which contains all the review processes of identifying the issue, finding the appropriate research studies, categorize and synthesize findings. The categories' descriptions, synthesized findings, and recommendations for practice were also included in the flowchart as per the JBI guidelines (The Joanna Briggs Institute, 2014) (Figure 2).

\section{Limitations of the Review}

While every effort was made to plan and undertake a comprehensive search strategy, there are some potential limitations for this review. The finally selected search terms might have led us to missing publications. However, every effort was made to include them using PICoS mnemonic, while designing the search query and pilot searches performed. In addition, only studies in English language were included which may have led to some bias too.

The small number of studies is certainly a limitation in itself to conclude and generalize results, but at the same time it demonstrates the need for further research in this topic. The review included five studies representing only four countries, all of which happened to be developing countries, but the fact that all the review's findings were strongly supported by lots of quantitative and mixed method worldwide studies compensates for the limited number of the included studies, and their countries of origin. A previous systematic review in 2016 included a majority of studies conducted in western countries (Vrbnjak et al., 2016), also confirming the findings of this review, while a global study on error reporting systems and barriers in 16 different countries from Africa, Australia, Europe, and North America showed a major commonality between perceived barriers to incident reporting (Holmström et al., 2012). Furthermore, a review in primary care identified that there is a lack of safety culture (Lainer et 
al., 2015) while studies supported partially the findings of this review both in primary care (Michel et al., 2017) and in long term care settings (Vaismoradi et al., 2020).

The methodological quality of the included studies was relatively good, apart from the relationship between the researcher and the participants; none of the five studies addressed potential bias in the research, and one study lacked a sampling strategy (Hashemi et al., 2012), which might influence the quality of the findings of this review. No studies were excluded according to their methodological quality assessment, which is considered a standard practice (Dixon-Woods et al., 2007).

The importance of incident reporting in health care is undisputed, being a very important pillar in improving health care systems and ensuring patient safety. This review identified several barriers to incident reporting among nurses. Fear of negative consequences such as blame and legal issues- was the most prominent barrier and the main reason contributing to the underreporting of nursing errors. Barriers also included managerial misconduct, inadequate incident reporting processes, and the lack of the necessary training and motivation required to implement an effective incident reporting system. This review findings agreed by previous systematic evidence showing that there is still a need to develop effective interventions and policies to overcome these barriers and encourage incident reporting among nurses. There should be a system's change and a cultural shift from individual blaming and pointing fingers to awareness, trust, sharing, and learning. 


\section{Reference List}

Aboshaiqah, A. E. (2013). Barriers in reporting medication administration errors as perceived by nurses in Saudi Arabia. Middle-East Journal of Scientific Research, 17(2), 130-136. https://doi.org/https://doi.org/10.9734/BJEMT/2016/22774

Ackerman, M. H. (2018). Silence: A Never Event. AACN Advanced Critical Care, 29(4), 449-451. https://doi.org/10.4037/aacnacc2018830

Almutary, H. H., \& Lewis, P. A. (2012). Nurses' willingness to report medication administration errors in Saudi Arabia. Quality Management in Health Care, 21(3), 119126. https://doi.org/10.1097/QMH.0b013e31825e86c8

Azadi, A., Anoosheh, M., \& Delpisheh, A. (2011). Frequency and barriers of underreported needlestick injuries amongst Iranian nurses, a questionnaire survey. Journal of Clinical Nursing, 20(3-4), 488-493. https://doi.org/https://doi.org/10.1111/j.13652702.2010.03252.x

Benn, J., Koutantji, M., Wallace, L., Spurgeon, P., Rejman, M., Healey, A., \& Vincent, C. (2009). Feedback from incident reporting: information and action to improve patient safety. BMJ Quality \& Safety, 18(1), 11-21.

https://doi.org/http://dx.doi.org/10.1136/qshc.2007.024166

Bifftu, B. B., Dachew, B. A., Tiruneh, B. T., \& Beshah, D. T. (2016). Medication administration error reporting and associated factors among nurses working at the University of Gondar referral hospital, Northwest Ethiopia, 2015. BMC Nuring, 15(43). https://doi.org/10.1186/s12912-016-0165-3

Brubacher, J. R., Hunte, G. S., Hamilton, L., \& Taylor, A. (2011). Barriers to and incentives for safety event reporting in emergency departments. Healthcare Quarterly (Toronto, Ont.), 14(3), 57-65. https://doi.org/https://doi.org/10.12927/hcq.2011.22491

Bryman, A., Stephens, M., \& a Campo, C. (1996). The importance of context: Qualitative 
research and the study of leadership. The Leadership Quarterly, 7(3), 353-370. https://doi.org/https://doi.org/10.1016/S1048-9843(96)90025-9

Chard, R. (2006). How Perioperative Define, Attribute Causes of, and React to Intraoperative Nursing Errors. AORN J, 91(1), 132-145. https://doi.org/doi:10.1016/j.aorn.2009.06.028

Chiang, H.-Y., Lin, S.-Y., Hsu, S.-C., \& Ma, S.-C. (2010). Factors determining hospital nurses' failures in reporting medication errors in Taiwan. Nursing Outlook, 58(1), 1725. https://doi.org/10.1016/j.outlook.2009.06.001

Chiang, H. (2005). Nurses' demographics and perceptions of safety climate, work environment, and barriers to medication administration error reporting in southern Taiwan. [University of Utah]. https://collections.lib.utah.edu/ark:/87278/s65q4z0d

Cleary, M., Lees, D., \& Lopez, V. (2018). "Saying Sorry": Some Strategies for Effective Apology within the Workplace. Issues in Mental Health Nursing, 39(11), 980-982. https://doi.org/10.1080/01612840.2018.1507571

Copping, C. (2005). Preventing and reporting drug administration errors. Nursing Times, 101(33), 32-34.

Dekker, S. (2016a). Patient safety: a human factors approach. CRC Press. https://doi.org/https://doi.org/10.1201/b10942

Dekker, S. (2016b). Just culture: Balancing safety and accountability (2nd ed). CRC Press. https://doi.org/10.4324/9781315251271

Dekker, S. (2018). Just Culture: Restoring Trust and Accountability in Your Organization (3rd ed). CRC Press. https://doi.org/10.1201/9781315590813

Dekker, S. W. A., \& Hugh, T. B. (2014). A just culture after Mid Staffordshire. BMJ Quality \& Safety, 23(5), 356 LP - 358. https://doi.org/10.1136/bmjqs-2013-002483

Dirik, H. F., Samur, M., Seren Intepeler, S., \& Hewison, A. (2019). Nurses’ identification and reporting of medication errors. Journal of Clinical Nursing, 28(5-6), 931-938. 
https://doi.org/10.1111/jocn.14716

Dixon-Woods, M., Shaw, R. L., Agarwal, S., \& Smith, J. A. (2004). The problem of appraising qualitative research. BMJ Quality \& Safety, 13(3), 223-225. https://doi.org/http://dx.doi.org/10.1136/qshc.2003.008714

Dixon-Woods, M., Sutton, A., Shaw, R., Miller, T., Smith, J., Young, B., Bonas, S., Booth, A., \& Jones, D. (2007). Appraising qualitative research for inclusion in systematic reviews: a quantitative and qualitative comparison of three methods. Journal of Health Services Research \& Policy, 12(1), 42-47. https://doi.org/https://doi.org/10.1258/135581907779497486

Dyab, E. A., Elkalmi, R. M., Bux, S. H., \& Jamshed, S. Q. (2018). Exploration of nurses' knowledge, attitudes, and perceived barriers towards medication error reporting in a tertiary health care facility: A qualitative approach. Pharmacy, 6(4), 120. https://doi.org/http://dx.doi.org/10.3390/pharmacy6040120

Elder, N. C., Brungs, S. M., Nagy, M., Kudel, I., \& Render, M. L. (2008). Nurses' perceptions of error communication and reporting in the intensive care unit. Journal of Patient Safety, 4(3), 162-168. https://doi.org/10.1097/PTS.0b013e3181839b48

Elkin, P. L., Johnson, H. C., Callahan, M. R., \& Classen, D. C. (2016). Improving patient safety reporting with the common formats: common data representation for patient safety organizations. Journal of Biomedical Informatics, 64, 116-121. https://doi.org/https://doi.org/10.1016/j.jbi.2016.09.020

Ellis, P., \& Abbott, J. (2019). Learning from mistakes III: taking on the learning. Journal of Kidney Care, 4(6), 339-341. https://doi.org/10.12968/jokc.2019.4.6.339

Evans, S. M., Berry, J. G., Smith, B. J., Esterman, A., Selim, P., O’Shaughnessy, J., \& DeWit, M. (2006). Attitudes and barriers to incident reporting: a collaborative hospital study. Quality \& Safety in Health Care, 15(1), 39-43. 
https://doi.org/http://dx.doi.org/10.1136/qshc.2004.012559

Farag, A., Blegen, M., Gedney-Lose, A., Lose, D., \& Perkhounkova, Y. (2017). Voluntary

Medication Error Reporting by ED Nurses: Examining the Association With Work

Environment and Social Capital. Journal of Emergency Nursing, 43(3), 246-254.

https://doi.org/10.1016/j.jen.2016.10.015

Fathi, A., Hajizadeh, M., Moradi, K., Zandian, H., Dezhkameh, M., Kazemzadeh, S., \& Rezaei, S. (2017). Medication errors among nurses in teaching hospitals in the west of Iran: what we need to know about prevalence, types, and barriers to reporting.

Epidemiology and Health, 39, e2017022-e2017022.

https://doi.org/10.4178/epih.e2017022

Fernandez, L. G., Sharifaridah, B. J., \& Nurashikin, S. (2010). Nurses perception towards reporting of near miss errors in medication administration-a qualitative study.

Proceedings of Singapore Healthcare, 19(Suppl. 2), S282-S282.

https://doi.org/http://dx.doi.org/10.1177/20101058100190S201

Firth-Cozens, J. (2002). Barriers to incident reporting. BMJ Quality \& Safety, 11(1), 7.

https://doi.org/http://dx.doi.org/10.1136/qhc.11.1.7

Florczak, K. L. (2019). Meta-Aggregation: Just What Is It? Nursing Science Quarterly, 32(1),

11. https://doi.org/https://doi.org/10.1177/0894318418807933

Fondahn, E., De Fer, T. M., Lane, M., \& Vannucci, A. (2016). Washington Manual of Patient Safety and Quality Improvement. Lippincott Williams \& Wilkins.

Fung, W. M., Koh, S. S. L., \& Chow, Y. L. (2012a). Attitudes and perceived barriers influencing incident reporting by nurses and their correlation with reported incidents: A systematic review. JBI Library of Systematic Reviews, 10(1), 1-65.

https://doi.org/10.11124/jbisrir-2012-44

Fung, W. M., Koh, S. S. L., \& Chow, Y. L. (2012b). Attitudes and perceived barriers 
influencing incident reporting by nurses and their correlation with reported incidents: A systematic review. JBI Library of Systematic Reviews, 10(1), 1-65.

https://doi.org/10.11124/jbisrir-2012-44

Galt, K. A., \& Paschal, K. A. (2009). Foundations in patient safety for health professionals. Jones \& Bartlett Publishers.

Gao, X., Yan, S., Wu, W., Zhang, R., Lu, Y., \& Xiao, S. (2019). Implications from China patient safety incidents reporting system. Therapeutics and Clinical Risk Management, 15, 259-267. https://doi.org/10.2147/TCRM.S190117

Gleeson, L., Dalton, K., O’Mahony, D., \& Byrne, S. (2019). Interventions to improve reporting of medication errors in hospitals: A systematic review and narrative synthesis. Research in Social and Administrative Pharmacy.

Grant, M. J. C., \& Larsen, G. Y. (2007). Effect of an anonymous reporting system on nearmiss and harmful medical error reporting in a pediatric intensive care unit. Journal of Nursing Care Quality, 22(3), 213-221. https://doi.org/https://doi.org/10.1097/01.ncq.0000277777.35395.e0

Hamilton, E. C., Pham, D. H., Minzenmayer, A. N., Austin, M. T., Lally, K. P., Tsao, K., \& Kawaguchi, A. L. (2018). Are we missing the near misses in the OR?-underreporting of safety incidents in pediatric surgery. Journal of Surgical Research, 221, 336-342. https://doi.org/https://doi.org/10.1016/j.jss.2017.08.005

Handler, S. M., Perera, S., Shansky, E. F., Studenski, S. A., Nace, D. A., Fridsma, D. B., \& Hanlon, J. T. (2007). Identifying modifiable barriers to medication error reporting in the nursing home setting. Journal Of The American Medical Directors Association, 8(9), 568-574. https://doi.org/10.1016/j.jamda.2007.06.009

Hannes, K., \& Lockwood, C. (2011). Pragmatism as the philosophical foundation for the Joanna Briggs meta-aggregative approach to qualitative evidence synthesis. Journal of 
Advanced Nursing, 67(7), 1632-1642. https://doi.org/https://doi.org/10.1111/j.13652648.2011.05636.x

Hashemi, F. (2008). Ethical response to nursing error. Iranian Journal of Medical Ethics and History of Medicine, 1(4), 31-46.

Hashemi, F., Nasrabadi, A. N., \& Asghari, F. (2012). Factors associated with reporting nursing errors in Iran: a qualitative study. BMC Nursing, 11, 20. https://doi.org/10.1186/1472-6955-11-20

Hesari, B., Ghodsi, H., Hoseinabadi, M., Chenarani, H., \& Ghodsi, A. (2015). A survey of nurses' perceptions of the causes of medication errors and barriers to reporting in hospitals affiliated to Neyshabur university of medical sciences, Iran. Journal of Kerman University of Medical Sciences, 22(1), 105-111.

Holmström, A.-R., Airaksinen, M., Weiss, M., Wuliji, T., Chan, X. H., \& Laaksonen, R. (2012). National and local medication error reporting systems - a survey of practices in 16 countries. Journal of Patient Safety, 8(4), 165-176. https://doi.org/https://doi.org/10.1097/pts.0b013e3182676cf3

Hwang, J.-I., Lee, S.-I., \& Park, H.-A. (2012). Barriers to the operation of patient safety incident reporting systems in korean general hospitals. Healthcare Informatics Research, 18(4), 279-286. https://doi.org/10.4258/hir.2012.18.4.279

International, J. C., \& Organizations, J. C. on A. of H. (2007). Joint Commission International accreditation standards for hospitals. Joint Commission Resources.

Israelski, E. (2010). Using human factors engineering to improve patient safety: problem solving on the front line, second edition, 2010. Biomedical Instrumentation \& Technology, 44(6), 474. https://doi.org/10.2345/0899-8205-44.6.474

Jeffe, D. B., Dunagan, W. C., Garbutt, J., Burroughs, T. E., Gallagher, T. H., Hill, P. R., Harris, C. B., Bommarito, K., \& Fraser, V. J. (2004). Using focus groups to understand 
physicians' and nurses' perspectives on error reporting in hospitals. Joint Commission Journal on Quality and Safety, 30(9), 471-479.

https://doi.org/https://doi.org/10.1016/s1549-3741(04)30055-9

Kingston, F. (2011). Nurse likelihood to report a pediatric medication error: Examinationof the “pre-reporting” period. UMI DIssertation Publishing, ProQuest.

Kreckler, S., Catchpole, K., McCulloch, P., \& Handa, A. (2009). Factors influencing incident reporting in surgical care. Quality \& Safety in Health Care, 18(2), 116-120. https://doi.org/10.1136/qshc.2008.026534

Leape, L. L. (2002). Reporting of adverse events. The New England Journal of Medicine, 347(20), 1633. https://doi.org/10.1056/NEJMNEJMhpr011493

Leape, L. L., \& Berwick, D. M. (2005). Five Years After To Err Is HumanWhat Have We Learned? JAMA, 293(19), 2384-2390. https://doi.org/10.1001/jama.293.19.2384

Lee, E. (2017). Reporting of medication administration errors by nurses in South Korean hospitals. International Journal for Quality in Health Care : Journal of the International Society for Quality in Health Care, 29(5), 728-734.

https://doi.org/10.1093/intqhe/mzx096

Lee, J. P.-C. (2018). Improving Medication Safety in an Inpatient Setting [California State University, Fullerton]. https://docplayer.net/amp/132526835-Southern-california-csudnp-consortium.html

Lin, Y., \& Ma, S. (2009). Willingness of Nurses to Report Medication Administration Errors in Southern Taiwan: A Cross-Sectional Survey. Worldviews on Evidence-Based Nursing, 6(4), 237-245. https://doi.org/https://doi.org/10.1111/j.17416787.2009.00169.x

Macrae, C. (2016). The problem with incident reporting. BMJ Qual Saf, 25(2), 71-75. https://doi.org/http://dx.doi.org/10.1136/bmjqs-2015-004732 
Malterud, K. (2001). Qualitative research: standards, challenges, and guidelines. The Lancet, 358(9280), 483-488. https://doi.org/10.1016/S0140-6736(01)05627-6

Mansouri, S. F., Mohammadi, T. K., Adib, M., Lili, E. K., \& Soodmand, M. (2019). Barriers to nurses reporting errors and adverse events. British Journal of Nursing (Mark Allen Publishing), 28(11), 690-695. https://doi.org/10.12968/bjon.2019.28.11.690

Marx, D. (2005). Just Culture. Laboratory Errors and Patient Safety, 1(6), 2-4.

Maurer, M. J. (2010). Nurses' perceptions of and experiences with medication errors [University of Toledo]. http://rave.ohiolink.edu/etdc/view?acc_num=toledo1279243109

Mayo, A. M., \& Duncan, D. (2004). Nurse perceptions of medication errors: what we need to know for patient safety. Journal of Nursing Care Quality, 19(3), 209-217. https://doi.org/https://doi.org/10.1097/00001786-200407000-00007

Methley, A. M., Campbell, S., Chew-Graham, C., McNally, R., \& Cheraghi-Sohi, S. (2014). PICO, PICOS and SPIDER: a comparison study of specificity and sensitivity in three search tools for qualitative systematic reviews. BMC Health Services Research, 14(1), 579. https://doi.org/https://doi.org/10.1186/s12913-014-0579-0

Michel, P., Brami, J., Chanelière, M., Kret, M., Mosnier, A., Dupie, I., Haeringer-Cholet, A., Keriel-Gascou, M., Maradan, C., Villebrun, F., Makeham, M., \& Quenon, J.-L. (2017). Patient safety incidents are common in primary care: A national prospective active incident reporting survey. PloS One, 12(2), e0165455-e0165455. https://doi.org/10.1371/journal.pone.0165455

Mitchell, I., Schuster, A., Smith, K., Pronovost, P., \& Wu, A. (2016). Patient safety incident reporting: a qualitative study of thoughts and perceptions of experts 15 years after 'To Err is Human.' BMJ Quality \& Safety, 25(2), 92-99. https://doi.org/https://doi.org/10.1136/bmjqs-2015-004405

Moher, D., Liberati, A., Tetzlaff, J., \& Altman, D. G. (2009). Preferred reporting items for 
systematic reviews and meta-analyses: the PRISMA statement. Annals of Internal Medicine, 151(4), 264-269.

https://doi.org/https://doi.org/10.1371/journal.pmed.1000097

Mostafaei, D., Marnani, A. B., Esfahani, H. M., Estebsari, F., Shahzaidi, S., Jamshidi, E., \& Aghamiri, S. S. (2014). Medication Errors of Nurses and Factors in Refusal to Report Medication Errors Among Nurses in a Teaching Medical Center of Iran in 2012. Iranian Red Crescent Medical Journal, 16(10). https://doi.org/10.5812/ircmj.16600

Moumtzoglou, A. (2010). Factors impeding nurses from reporting adverse events. Journal of Nursing Management, 18(5), 542-547. https://doi.org/https://doi.org/10.1111/j.13652834.2010.01049.x

Munn, Z., Porritt, K., Lockwood, C., Aromataris, E., \& Pearson, A. (2014). Establishing confidence in the output of qualitative research synthesis: the ConQual approach. $B M C$ Medical Research Methodology, 14(1), 108. https://doi.org/https://doi.org/10.1186/1471-2288-14-108

No Author. (2018). Critical Appraisal Skills Programme (CASP) Qualitative Research Checklist. https://casp-uk.net/casp-tools-checklists/

Noble, D. J., \& Pronovost, P. J. (2010). Underreporting of patient safety incidents reduces health care's ability to quantify and accurately measure harm reduction. Journal of Patient Safety, 6(4), 247-250.

https://doi.org/https://doi.org/10.1097/pts.0b013e3181fd1697

nstitute of Medicine (US) Committee on Quality of Health Care in America. (2000). To err is human: building a safer health system (L. T. Kohn, J. Corrigan, \& M. S. Donaldson (eds.); Vol. 6). National academy press.

Parmelli, E., Flodgren, G., Fraser, S. G., Williams, N., Rubin, G., \& Eccles, M. P. (2012). Interventions to increase clinical incident reporting in health care. Cochrane Database 
of Systematic Reviews, 8 .

https://doi.org/https://doi.org/10.1002/14651858.cd005609.pub2

Parse, R. R., Coyne, A. B., \& Smith, M. J. (1985). Nursing research: Qualitative methods. Brady.

Pearson, A., Wiechula, R., Court, A., \& Lockwood, C. (2005). The JBI model of evidencebased healthcare. International Journal of Evidence-Based Healthcare, 3(8), 207-215. https://doi.org/https://doi.org/10.1111/j.1479-6988.2005.00026.x

Petrova, E. (2010). Nurses' perceptions of medication errors in Malta. Nursing Standard (Royal College of Nursing (Great Britain) : 1987), 24(33), 41-48.

https://doi.org/10.7748/ns2010.04.24.33.41.c7717

Peyrovi, H., Nasrabadi, A. N., \& Valiee, S. (2016). Exploration of the barriers of reporting nursing errors in intensive care units: A qualitative study. Journal of the Intensive Care Society, 17(3), 215-221. https://doi.org/10.1177/1751143716638370

Pham, J. C., Gianci, S., Battles, J., Beard, P., Clarke, J. R., Coates, H., Donaldson, L., Eldridge, N., Fletcher, M., \& Goeschel, C. A. (2010). Establishing a global learning community for incident-reporting systems. BMJ Quality \& Safety, 19(5), 446-451.

Pope, C., \& Mays, N. (2006). Qualitative Research in Health Care. Blackwell Publishing Ltd. https://doi.org/10.1002/9780470750841

Qin, C., Xie, J., Jiang, J., Zhen, F., \& Ding, S. (2015). Reporting among nurses and its correlation with hospital safety culture. Journal of Nursing Care Quality, 30(1), 77-83. https://doi.org/10.1097/NCQ.0000000000000068

Reason, J. (2000). Human error: models and management. BMJ, 320(7237), 768-770. https://doi.org/https://doi.org/10.1136/bmj.320.7237.768

Reason, J. (2016). Managing the Risks of Organizational Accidents. Routledge.

Rohde, E., \& Domm, E. (2018). Nurses' clinical reasoning practices that support safe 
medication administration: An integrative review of the literature. Journal of Clinical Nursing, 27(3-4), e402-e411. https://doi.org/10.1111/jocn.14077

Rutledge, D. N., Retrosi, T., \& Ostrowski, G. (2018). Barriers to medication error reporting among hospital nurses. Journal of Clinical Nursing, 27(9-10), 1941-1949. https://doi.org/10.1111/jocn.14335

Sanghera, I. S., Franklin, B. D., \& Dhillon, S. (2007). The attitudes and beliefs of healthcare professionals on the causes and reporting of medication errors in a UK Intensive care unit. Anaesthesia, 62(1), 53-61. https://doi.org/10.1111/j.1365-2044.2006.04858.x

Shorten, A., \& Smith, J. (2017). Mixed methods research: expanding the evidence base. Evidence Based Nursing, 20(3), 74 LP - 75. https://doi.org/10.1136/eb-2017-102699

Song, J., \& Guo, Y. (2019). What influences nursing safety event reporting among nursing interns?: Focus group study. Nurse Education Today, 76, 200-205. https://doi.org/10.1016/j.nedt.2019.02.010

Stavropoulou, C., Doherty, C., \& Tosey, P. (2015). How effective are incident-reporting systems for improving patient safety? A systematic literature review. The Milbank Quarterly, 93(4), 826-866. https://doi.org/https://doi.org/10.1111/1468-0009.12166

Stelfox, H. T., Palmisani, S., Scurlock, C., Orav, E. J., \& Bates, D. W. (2006). The "To Err is Human" report and the patient safety literature. Quality and Safety in Health Care, 15(3), 174 LP - 178. https://doi.org/10.1136/qshc.2006.017947

Sutcliffe, K. M., Paine, L., \& Pronovost, P. J. (2017). Re-examining high reliability: actively organising for safety. BMJ Quality \&amp;Amp; Safety, 26(3), 248 LP - 251. https://doi.org/10.1136/bmjqs-2015-004698

The Joanna Briggs Institute. (2014). Joanna Briggs Institute Reviewers’ Manual: 2014 edition (4th ed.). The Joanna Briggs Institute.

Thomas, M. B. (2010). Registered nurses select multiple factors associated with their errors. 
Critical Care Nursing Clinics, 22(2), 279-282.

https://doi.org/ttps://doi.org/10.1016/j.ccell.2010.03.010

Tong, A., Flemming, K., McInnes, E., Oliver, S., \& Craig, J. (2012). Enhancing transparency in reporting the synthesis of qualitative research: ENTREQ. BMC Medical Research Methodology, 12(1), 181. https://doi.org/https://doi.org/10.1186/1471-2288-12-181

Vaismoradi, M., Vizcaya-Moreno, F., Jordan, S., Gåre Kymre, I., \& Kangasniemi, M. (2020). Disclosing and Reporting Practice Errors by Nurses in Residential Long-Term Care Settings: A Systematic Review. Sustainability, 12(7), 2630.

https://doi.org/10.3390/su12072630

Vincent, C. (2011). Patient safety. John Wiley \& Sons.

Vrbnjak, D., Denieffe, S., O’Gorman, C., \& Pajnkihar, M. (2016). Barriers to reporting medication errors and near misses among nurses: A systematic review. International Journal of Nursing Studies, 63, 162-178. https://doi.org/10.1016/j.ijnurstu.2016.08.019

Wachter, R. M. (2012). Understanding patient safety (2nd ed.). McGraw-Hill Medical.

Wakefield, D. S., Wakefield, B. J., Uden-Holman, T., \& Blegen, M. A. (1996). Perceived barriers in reporting medication administration errors. Best Practices and Benchmarking in Healthcare, 1(4), 191-197.

Wallace, L. (2010). Feedback from reporting patient safety incidents--are NHS trusts learning lessons? Journal of Health Services Research \& Policy, 15 Suppl 1, 75-78. https://doi.org/10.1258/jhsrp.2009.09s113

Wolf, Z., \& Hughes, R. (2008). Error Reporting and Disclosure. In R. Hughes (Ed.), Patient Safety and Quality: An Evidence-Based Handbook for Nurses (p. Chapter 35). Agency for Healthcare Research and Quality. https://www.ncbi.nlm.nih.gov/books/NBK2652/ World Health Organization (WHO). (2005). World alliance for patient safety: WHO draft guidelines for adverse event reporting and learning systems: from information to action. 
World Health Organization.

https://apps.who.int/iris/bitstream/handle/10665/69797/WHO-EIP-SPO-QPS-05.3eng.pdf? sequence $=1 \&$ is Allowed $=y$

World Health Organization (WHO). (2018). 10 Facts on Patient Safety.

https://www.who.int/features/factfiles/patient_safety/en/

Yumei, G., Yanling, T., \& Juanhui, C. (2016). Status quo of nursing personnel medication errors reporting obstacles and analysis of its personal factors. Chinese Nursing Research, 30(4C), 1437-1441. https://doi.org/10.3969/j.issn.1009-6493.2016.12.010

Yung, H.-P., Yu, S., Chu, C., Hou, I.-C., \& Tang, F.-I. (2016). Nurses' attitudes and perceived barriers to the reporting of medication administration errors. Journal of Nursing Management, 24(5), 580-588. https://doi.org/10.1111/jonm.12360 


\section{Tables}

Table 1. Summary of the Appraisal of the Included Studies

\begin{tabular}{|c|c|c|c|c|c|}
\hline Question Study & $\begin{array}{l}\text { Hashemi et } \\
\text { al., } 2012\end{array}$ & $\begin{array}{l}\text { Hwang et al., } \\
\quad 2012\end{array}$ & $\begin{array}{l}\text { Peyrovi et al., } \\
\quad 2016\end{array}$ & $\begin{array}{l}\text { Dyab et al., } \\
2018\end{array}$ & $\begin{array}{l}\text { Song et al., } \\
2019\end{array}$ \\
\hline $\begin{array}{l}\text { 1. Was there a clear } \\
\text { statement of the aims of } \\
\text { the research? }\end{array}$ & Yes & Yes & Yes & Yes & Yes \\
\hline $\begin{array}{ll}2 . & \text { Is a qualitative } \\
& \text { methodology appropriate? }\end{array}$ & Yes & Yes & Yes & Yes & Yes \\
\hline $\begin{array}{l}\text { 3. Was the research design } \\
\text { appropriate to address the } \\
\text { aims of the research? }\end{array}$ & Yes & Unclear & Yes & Yes & Yes \\
\hline $\begin{array}{l}\text { 4. Was the recruitment } \\
\text { strategy appropriate to the } \\
\text { aims of the research? }\end{array}$ & No & Yes & Unclear & Yes & Unclear \\
\hline $\begin{array}{l}\text { 5. Was the data collected in } \\
\text { a way that addressed the } \\
\text { research issue? }\end{array}$ & Yes & Yes & Yes & Yes & Yes \\
\hline $\begin{array}{l}\text { 6. Has the relationship } \\
\text { between researcher and } \\
\text { participants been } \\
\text { adequately considered? }\end{array}$ & No & No & No & No & No \\
\hline $\begin{array}{l}\text { 7. Have ethical issues been } \\
\text { taken into consideration? }\end{array}$ & Yes & Yes & Yes & Yes & Yes \\
\hline $\begin{array}{ll}\text { 8. Was the data analysis } \\
\text { sufficiently rigorous? }\end{array}$ & Yes & Yes & Yes & Yes & No \\
\hline $\begin{array}{ll}\text { 9. Was there a clear } \\
\text { statement of findings? }\end{array}$ & Yes & Yes & Yes & Yes & Yes \\
\hline $\begin{array}{l}\text { 10. How valuable was the } \\
\text { research? }\end{array}$ & $\begin{array}{l}\text { Has Some } \\
\text { Value }\end{array}$ & $\begin{array}{l}\text { Has Some } \\
\text { Value }\end{array}$ & Valuable & $\begin{array}{l}\text { Has some } \\
\text { value }\end{array}$ & $\begin{array}{l}\text { Has Some } \\
\text { Value }\end{array}$ \\
\hline
\end{tabular}

Valuable: Study meets all three criteria: the researcher discusses the contribution the study makes to existing knowledge or understanding; identify new areas where research is necessary; the researchers have discussed whether or how the findings can be transferred to other populations or considered other ways the research may be used.

Has Some Value: Study meets at least two of the above criteria. 
Table 2: Summary of Study Characteristics

\begin{tabular}{|c|c|c|c|c|c|c|}
\hline & $\begin{array}{l}\text { Author } \\
\text { (Year) }\end{array}$ & Country/ Setting & Phenomena of Interest & Participants & $\begin{array}{l}\text { Data Collection / } \\
\text { Data Analysis }\end{array}$ & Study Conclusion \\
\hline 1 & $\begin{array}{l}\text { Hashemi } \\
\text { et al., } \\
2012\end{array}$ & $\begin{array}{l}\text { Iran/ } \\
2 \text { hospitals affiliated to } \\
\text { Tehran and Shiraz } \\
\text { Universities of Medical } \\
\text { Sciences }\end{array}$ & $\begin{array}{l}\text { To explore factors associated } \\
\text { with error reporting among } \\
\text { nurses }\end{array}$ & $\begin{array}{l}\text { Total } N=115 \text { nurses } \\
\text { - working experience of } 3 \text { to } 27 \\
\text { years } \\
\text { - } n=80 \text { nurses and head nurses } \\
\text { in wards and specialized clinics } \\
\text { - } n=35 \text { matrons and supervisors } \\
\text { working in all hospitals and } \\
\text { specialized clinics of the two } \\
\text { universities }\end{array}$ & $\begin{array}{l}17 \text { Focus group } \\
\text { discussions/ } \\
\text { Inductive Content } \\
\text { Analysis }\end{array}$ & $\begin{array}{l}\text { The process of error reporting provides extremely } \\
\text { valuable information for preventing future errors, } \\
\text { and concerning barriers to error reporting, it is } \\
\text { important to enact regulations that clearly identify } \\
\text { the optimal ways of error reporting }\end{array}$ \\
\hline 2 & $\begin{array}{l}\text { Hwang et } \\
\text { al., } 2012\end{array}$ & $\begin{array}{l}\text { Korea/42 general hospitals } \\
\text { in Korea }\end{array}$ & $\begin{array}{l}\text { To explore barriers and } \\
\text { facilitators to patient safety } \\
\text { incident reporting systems }\end{array}$ & $\begin{array}{l}\text { Total } n=42 \text { nurses } \\
\text { - } n=32 \text { in private hospitals } \\
-n=10 \text { in public hospitals } \\
-40 \text { nurses } 10 \text { or more years of } \\
\text { experience } \\
-40 \text { nurses held managerial } \\
\text { position }\end{array}$ & $\begin{array}{l}\text { Methodological } \\
\text { triangulation; } \\
\text { Interviews as well } \\
\text { as email/ } \\
\text { Qualitative Content } \\
\text { Analysis }\end{array}$ & $\begin{array}{l}\text { The barriers and facilitators for incident reporting } \\
\text { among nurses include various individual as well } \\
\text { as organizational factors, and the way to address } \\
\text { them is to improve the incident reporting system in } \\
\text { the hospitals }\end{array}$ \\
\hline 3 & $\begin{array}{l}\text { Peyrovi } \\
\text { et al., } \\
2016\end{array}$ & $\begin{array}{l}\text { Iran/ } \\
4 \text { general intensive care } \\
\text { units in } 4 \text { teaching } \\
\text { hospitals in Kurdistan and } \\
\text { Tehran provinces }\end{array}$ & $\begin{array}{l}\text { To explore the barriers of } \\
\text { reporting nursing errors in the } \\
\text { ICUs of Iranian hospitals }\end{array}$ & $\begin{array}{l}\text { Total } \mathrm{N}=16 \text { registered nurses } \\
\text { - Mean work experience }=9.56 \\
\text { years }\end{array}$ & $\begin{array}{l}\text { In-depth semi- } \\
\text { structured } \\
\text { interviews/ } \\
\text { Conventional } \\
\text { Content Analysis } \\
\end{array}$ & $\begin{array}{l}\text { Managers must provide to all nurses security, } \\
\text { personal, professional and legal support in order } \\
\text { to encourage them to report errors effectively, } \\
\text { discover their root causes, and take measures to } \\
\text { prevent them }\end{array}$ \\
\hline 4 & $\begin{array}{l}\text { Dyab et } \\
\text { al., } 2018\end{array}$ & $\begin{array}{l}\text { Malaysia/ A tertiary health } \\
\text { care facility of Kuantan } \\
\text { city, Pahang }\end{array}$ & $\begin{array}{l}\text { To investigate the barriers to } \\
\text { nurses' error reporting as well } \\
\text { as to attain deeper insight into } \\
\text { nurses' knowledge and } \\
\text { attitudes towards medication } \\
\text { errors and medication error } \\
\text { reporting processes }\end{array}$ & $\begin{array}{l}\text { Total } \mathrm{N}=23 \text { nurses } \\
-12 \text { nurses more than } 11 \text { years } \\
\text { of working experience } \\
-18 \text { not reported any } \\
\text { medication errors in the prior } 12 \\
\text { months }\end{array}$ & $\begin{array}{l}21 \text { In-depth semi- } \\
\text { structured } \\
\text { interviews/ } \\
\text { Inductive Thematic } \\
\text { Analysis }\end{array}$ & $\begin{array}{l}\text { The attitude of the nurses greatly affects their } \\
\text { reporting. Reasons for underreporting include high } \\
\text { workload, types of forms, fear of investigation, } \\
\text { absence of feedback, embarrassment, lack of } \\
\text { time. Developing a blame-free culture as well as } \\
\text { achieving confidentiality of the reporters are some } \\
\text { identified strategies to medication error reporting }\end{array}$ \\
\hline 5 & $\begin{array}{l}\text { Song et } \\
\text { al., } 2019\end{array}$ & $\begin{array}{l}\text { China/ } \\
\text { One medical university in } \\
\text { Fuzhou (participants } \\
\text { interned in different tertiary } \\
\text { hospitals in Fuzhou) } \\
\end{array}$ & $\begin{array}{l}\text { To explore barriers to and } \\
\text { incentives for nursing interns } \\
\text { safety event reporting }\end{array}$ & $\begin{array}{l}\text { Total } N=38 \text { nursing interns } \\
\text { All completed six months of } \\
\text { training in one of three Fuzhou } \\
\text { Tertiary Hospitals }\end{array}$ & $\begin{array}{l}6 \text { Focus group } \\
\text { discussions/ } \\
\text { Inductive and } \\
\text { Deductive Content } \\
\text { Analysis }\end{array}$ & $\begin{array}{l}\text { Practical and targeted management strategies } \\
\text { need to be implemented to foster reporting and } \\
\text { improve patient safety. Nursing schools need to } \\
\text { establish incident reporting systems for interns }\end{array}$ \\
\hline
\end{tabular}


Table 3. Meta Aggregation of the Nurses' Barriers to Error Reporting

\begin{tabular}{|c|c|c|c|}
\hline $\begin{array}{c}\text { Findings (Barriers to Nursing Error } \\
\text { Reporting) } \\
\end{array}$ & Illustration & Categories & $\begin{array}{l}\text { Synthesised } \\
\text { Findings }\end{array}$ \\
\hline Fear of threats and legal action (U) & $\begin{array}{l}\text { "If we report errors, they will be used against us. There will be no legal protection. They threaten us. Our problems will be examined in } \\
\text { the Medical Council. Physicians will vote against us and in favor of their own interest. We are afraid of being ousted from our job. } \\
\text { Continuous warning comes from the nursing office" (Hashemi et al., 2012, p.3) }\end{array}$ & \multirow{7}{*}{ Fear } & \multirow{16}{*}{$\begin{array}{l}\text { There is a fear } \\
\text { among nurses } \\
\text { of the } \\
\text { negative } \\
\text { consequences } \\
\text { of reporting } \\
\text { from their co- } \\
\text { workers and } \\
\text { supervisors }\end{array}$} \\
\hline Fear of economic losses $(U)$ & $\begin{array}{l}\text { "A nurse had to pay } \$ 8000 \text { as blood money because of a mistake which was not only his fault. How much is our income to pay blood } \\
\text { money" (Hashemi et al., 2012, p.3) }\end{array}$ & & \\
\hline Fear of being stigmatised $(U)$ & $\begin{array}{l}\text { "... Projection means you see staff around yourself or doctors that relate everything to that error you made ...." (Peyrovi et al., 2016, } \\
\text { p.3) }\end{array}$ & & \\
\hline Fear of punishment $(U)$ & "we believe that there is a series of punishments implemented following error reporting ..." (Peyrovi et al., 2016, p.4) & & \\
\hline Fear of legal problems (U) & $\begin{array}{l}\text { "... They take a nurse to court! I don't know what happened then, but the nurse got in trouble, I fear that the same thing would happen } \\
\text { to me..." (Peyrovi et al., 2016, p.4) }\end{array}$ & & \\
\hline Fear of organisational misconduct $(U)$ & "If we report our errors, the authorities would have improper behaviour towards me!" (Peyrovi et al., 2016, p.4) & & \\
\hline $\begin{array}{l}\text { Fear of disciplinary action (e.g. legal } \\
\text { problems) }(\mathrm{U})\end{array}$ & "I fear from legal problems and disciplinary actions from the hospital." (Dyab et al., 2018, p.8) & & \\
\hline $\begin{array}{l}\text { Previous inadequate reactions from } \\
\text { the organisation }(U)\end{array}$ & $\begin{array}{l}\text { "When we report our errors, we face harsh and unfair behaviors (warnings, threats, etc.). Should an error be reported in such a } \\
\text { milieu?!" (Hashemi et al., 2012, p.4) }\end{array}$ & \multirow{9}{*}{$\begin{array}{l}\text { Managerial } \\
\text { Misconduct }\end{array}$} & \\
\hline Blame culture $(\mathrm{C})$ & $\begin{array}{l}\text { "Being at the sharp end, being named, blamed, and shamed, and being humiliated were expressed by the participants" (Hashemi et al., } \\
\text { 2012, p.4) }\end{array}$ & & \\
\hline $\begin{array}{l}\text { Blame and punishment for the person } \\
\text { involved in the incident }(C)\end{array}$ & $\begin{array}{l}\text { "An organisational cultural practice of blaming and penalizing the department heads as well as those involved in medical errors was } \\
\text { frequently reported" (Hwang et al., 2012, p.284). }\end{array}$ & & \\
\hline Pointing fingers at nurses $(U)$ & $\begin{array}{l}\text { "Based on my experiences in intensive care, the nurse was scolded even if it was medical error considered as nursing errors! They first } \\
\text { considered an error to be a nursing error, and then if they could not prove it, they considered it as medical error." (Peyrovi et al., 2016, } \\
\text { p.4) }\end{array}$ & & \\
\hline Lack of managerial support $(U)$ & $\begin{array}{l}\text { "Because whenever there was a problem, all wanted to be acquitted, there was selfishness and nobody wanted to support you!" } \\
\text { (Peyrovi et al., 2016, p.4) }\end{array}$ & & \\
\hline $\begin{array}{l}\text { Lack of attention to the cause of the } \\
\text { error }(U)\end{array}$ & $\begin{array}{l}\text { "Nobody ever asks the real reasons for nursing errors; nobody asks me if I was tired when I committed the error? Was there any } \\
\text { excessive workload on you? What is your problem? .. Unfortunately, it's not important!" (Peyrovi et al., 2016, p.4) }\end{array}$ & & \\
\hline Failure to follow the origin of error $(U)$ & "... Because the origins of nursing errors remain unknown, there is no desire for reporting ..." (Peyrovi et al., 2016, p.4) & & \\
\hline $\begin{array}{l}\text { Negative reaction from in-charge } \\
\text { nurses }(U)\end{array}$ & "The sister will monitor me more." (Dyab et al., 2018, p.9) & & \\
\hline Absence of effective feedback (U) & "No one goes through all the errors and give me a feedback." (Dyab et al., 2018, p.9) & & \\
\hline
\end{tabular}




\begin{tabular}{|c|c|c|c|}
\hline Work pressure (U) & $\begin{array}{l}\text { "We are really busy; a great number of patients and a limited number of staff. We do not have time for reporting the errors and being } \\
\text { involved in the process of error reporting. Doing something for the patient in this little time is my concern" (Hashemi et al., 2012, p.4) }\end{array}$ & \multirow{13}{*}{$\begin{array}{l}\text { Inadequate } \\
\text { Organisational } \\
\text { Reporting } \\
\text { System }\end{array}$} & \multirow{20}{*}{$\begin{array}{l}\text { There is a } \\
\text { lack of the } \\
\text { organisational } \\
\text { support } \\
\text { needed to } \\
\text { foster an } \\
\text { incident } \\
\text { reporting } \\
\text { milieu for } \\
\text { nurses }\end{array}$} \\
\hline Lack of time $(U)$ & $\begin{array}{l}\text { "We are really busy; a great number of patients and a limited number of staff. We do not have time for reporting the errors and being } \\
\text { involved in the process of error reporting. Doing something for the patient in this little time is my concern" (Hashemi et al., 2012, p.4) }\end{array}$ & & \\
\hline $\begin{array}{l}\text { Time-consuming reporting process } \\
\text { (C) }\end{array}$ & "These factors include the personnel's lack of time and the reporting process' being time-consuming" (Hashemi et al., 2012, p.4) & & \\
\hline No assurance of anonymity $(\mathrm{C})$ & $\begin{array}{l}\text { "These incident reporting systems required reporters to identify themselves, participants were often dissuaded from reporting incidents" } \\
\text { (Hwang et al., 2012, p.284). }\end{array}$ & & \\
\hline $\begin{array}{l}\text { No integrated, dual reporting system } \\
\text { (C) }\end{array}$ & $\begin{array}{l}\text { 'Insufficient or partial integration between newly computerised reporting systems and conventional reporting systems seems to prevent } \\
\text { efficient incident reporting in busy clinical situations' (Hwang et al., 2012, p.284). }\end{array}$ & & \\
\hline $\begin{array}{l}\text { Difficulty to report multi-department } \\
\text { involved incidents }(C)\end{array}$ & $\begin{array}{l}\text { "Reporting systems had difficulty in integrating the reports that involved multiple departments and providing timely information to the } \\
\text { person responsible for managing incident reporting" (Hwang et al., 2012, p.284). }\end{array}$ & & \\
\hline Low reporting rate $(U)$ & The number of reporting near misses is particularly low" (Hwang et al., 2012, p.282) & & \\
\hline Heavy workload (C) & "These barriers include heavy workload" (Dyab et al., 2018, p.8) & & \\
\hline Lack of time $(U)$ & "...We do not have time for reporting. It is a long story and takes much time" (Dyab et al., 2018, p.8) & & \\
\hline Tiredness (U) & "Sometimes, we are tired. Once we are tired we decide not to report." (Dyab et al., 2018, p.8) & & \\
\hline Lack of confidentiality (U) & $\begin{array}{l}\text { "I prefer to fill anonymous form [. . . ] Because I feel shy and would not work further. Also, I would feel sorry for the patient. So, I prefer to } \\
\text { fill the form without names." (Dyab et al., 2018, p.9) }\end{array}$ & & \\
\hline $\begin{array}{l}\text { The inconvenience of the reporting } \\
\text { system (U) }\end{array}$ & "We have to report it (the event) twice, which makes me fidgety" (Song et al., 2019, p.202) & & \\
\hline No benefit from reporting $(U)$ & $\begin{array}{l}\text { "Subsequent solutions are my concern. The reporting system should be associated with patient information e.g., HIV or TP, which } \\
\text { would allow me to determine what to do next" (Song et al., 2019, p.202) }\end{array}$ & & \\
\hline $\begin{array}{l}\text { Lack of cooperation from clinical } \\
\text { departments }(C)\end{array}$ & $\begin{array}{l}\text { "Other perceived barriers included interdepartmental conflict and lack of interdepartmental cooperation, incident reporting being used } \\
\text { only in the nursing department" (Hwang et al., 2012, p.284). }\end{array}$ & \multirow{4}{*}{$\begin{array}{l}\text { Lack of } \\
\text { Cooperation }\end{array}$} & \\
\hline $\begin{array}{l}\text { Middle-level managers' lack of } \\
\text { knowledge and skills of patient safety } \\
\text { and incident reporting }(\mathrm{C})\end{array}$ & $\begin{array}{l}\text { "Department managers can control reporting processes by accepting or rejecting a specific incident report in a formal reporting line. } \\
\text { Their awareness and attitude towards incident reporting directly influences the reporting practices of their staff' (Hwang et al., 2012, } \\
\text { p.282) }\end{array}$ & & \\
\hline $\begin{array}{l}\text { Lack of physician's reporting and } \\
\text { participation }(\mathrm{C})\end{array}$ & "The lack of physicians' participation in incident reporting was described as a problem” (Hwang et al., 2012, p.282) & & \\
\hline Social influence (U) & "At first, we did not know how to deal with these problems; we often followed the teacher's guidance" (Song et al., 2019, p.202) & & \\
\hline $\begin{array}{l}\text { The weakness of knowledge and } \\
\text { nursing skills }(U)\end{array}$ & $\begin{array}{l}\text { "Someone may not be aware of his mistake and does not report it". "Nurses have little knowledge in this field. The educational system } \\
\text { has shortcomings" (Hashemi et al., 2012, p.3) }\end{array}$ & \multirow{3}{*}{$\begin{array}{l}\text { Lack of } \\
\text { Knowledge }\end{array}$} & \\
\hline Lack of knowledge $(U)$ & $\begin{array}{l}\text { "No one informed me of the criteria (for what should be reported). ... The error tends to be reported if the medicine entered the patient's } \\
\text { body since the patient must then be observed closely" (Song et al., 2019, p.202) }\end{array}$ & & \\
\hline $\begin{array}{l}\text { Lack of staffs knowledge and skill } \\
\text { related to incident reporting }(C)\end{array}$ & $\begin{array}{l}\text { "most hospital staff lack the knowledge and skills required for effective incident reporting (e.g., knowledge of sentinel events and near } \\
\text { misses)" (Hwang et al., 2012, p.282) }\end{array}$ & & \\
\hline
\end{tabular}




\begin{tabular}{|c|c|c|c|c|}
\hline $\begin{array}{l}\text { The ambiguity of the notion of error } \\
\text { (U) }\end{array}$ & \multicolumn{2}{|c|}{$\begin{array}{l}\text { "most hospital stafflack the knowledge and skills required for effective incident reporting (e.g., knowledge of sentinel events and near } \\
\text { misses)" (Hwang et al., 2012, p.282)"Something might be right in my opinion, but you or the head nurse considers it as an error! We } \\
\text { should know what an error is!! For example, if a patient is drugged with delay due to the crowdedness of the wards, is it an error?" } \\
\text { (Hashemi et al., 2012, p.4) }\end{array}$} & \multirow[t]{3}{*}{$\begin{array}{l}\text { Ambiguity of } \\
\text { an 'error' }\end{array}$} & \multirow[t]{3}{*}{$\begin{array}{l}\text { reporting } \\
\text { system }\end{array}$} \\
\hline Late reporting $(\mathrm{U})$ & \multicolumn{2}{|c|}{ "The first barrier is the omission of reporting incidents" (Hwang et al., 2012, p.282) } & & \\
\hline Low severity of error $(\mathrm{U})$ & \multicolumn{2}{|c|}{ "When an error with no serious outcome is practiced and everything is under control, no report is needed" (Hashemi et al., 2012, p.4) } & & \\
\hline $\begin{array}{l}\text { Unwillingness to accept the } \\
\text { responsibilities of the error }(U)\end{array}$ & \multicolumn{2}{|c|}{ "The personnel are different; it depends on an individual's sense of responsibility and commitment to work" (Hashemi et al., 2012, p.3) } & \multirow{2}{*}{$\begin{array}{l}\text { Unmotivated } \\
\text { and } \\
\text { Uncommitted } \\
\text { Nurses }\end{array}$} & \multirow{4}{*}{$\begin{array}{l}\text { Nurses lack } \\
\text { the motivation } \\
\text { needed to } \\
\text { ensure their } \\
\text { active } \\
\text { participation in } \\
\text { the incident } \\
\text { reporting } \\
\text { system }\end{array}$} \\
\hline Saving professional reputation (U) & $\begin{array}{l}\text { "If I tell the doctor that such and such nurse administers mann } \\
\text { the nurses as if the nurse is really careless and intentionally m }\end{array}$ & $\begin{array}{l}\text { do for the patient now? He/she pessimistically looks at } \\
\text { es" (Peyrovi et al., 2016, p.3 2) }\end{array}$ & & \\
\hline Embarrassment (U) & \multicolumn{2}{|c|}{ "Facing the embarrassment from my family and friends is tough. They will blame us." (Dyab et al., 2018, p.8) } & \multirow[b]{2}{*}{$\begin{array}{l}\text { Personal } \\
\text { Feelings }\end{array}$} & \\
\hline $\begin{array}{l}\text { The feeling of uncertainty, dishonour } \\
\text { and shame }(U)\end{array}$ & $\begin{array}{l}\text { "If I reported all nursing safety events, hospital recruiters will re } \\
\text { remember the mistake" (Song et al., 2019, p.202) }\end{array}$ & "It was humiliating. I still feel embarrassed when I & & \\
\hline \multicolumn{3}{|l|}{ Lack of system accessibility (UN) } & \multirow{13}{*}{\multicolumn{2}{|c|}{$\begin{array}{l}\text { Excluded from Synthesised } \\
\text { Findings }\end{array}$}} \\
\hline \multicolumn{2}{|l|}{ Usability problem (UN) } & \multirow{12}{*}{ Findings were not supported by data } & & \\
\hline \multicolumn{2}{|c|}{ Conflict due to which department are responsible for the incident (UN) } & & & \\
\hline \multicolumn{2}{|c|}{ Lack of reporting by the other department except nursing department (UN) } & & & \\
\hline \multicolumn{2}{|c|}{ Intractable cases within time and financial constraints (UN) } & & & \\
\hline \multicolumn{2}{|c|}{ Absence of fulltime patient safety officers (UN) } & & & \\
\hline \multicolumn{2}{|c|}{ Delayed feedback (UN) } & & & \\
\hline \multicolumn{2}{|c|}{ Absence of education and training opportunities on patient safety and incident reporting (UN) } & & & \\
\hline \multicolumn{2}{|c|}{ Middle-level managers' lack of knowledge and skills of patient safety and incident reporting (UN) } & & & \\
\hline \multicolumn{2}{|c|}{ Top-level managers: lack of patient safety leadership (UN) } & & & \\
\hline \multicolumn{2}{|c|}{ Lack of staff awareness of the importance of patient safety incident reporting (UN) } & & & \\
\hline \multicolumn{2}{|c|}{ Fear of blame, stress (UN) } & & & \\
\hline \multicolumn{2}{|c|}{ Insufficient knowledge and skills related to incident reporting of risk managers (UN) } & & & \\
\hline
\end{tabular}

$U=$ Unequivocal: where findings were accompanied by an illustration that is beyond reasonable doubt and; therefore, not open to challenge.

$\mathrm{C}=$ Credible: where findings were accompanied by an illustration lacking clear association with it and therefore open to challenge. 
UN = Unsupported: where findings were not supported by data. 
Table 4: Summary of Review Findings / GRADE ConQual Assessment

Systematic Review Title: Barriers to Incident Reporting among Nurses

Population: All Types of Nurses

Phenomenon of Interest: Barriers to Incident Reporting

Context: All Countries, and all Health Care Settings

\begin{tabular}{|c|c|c|c|c|c|c|c|}
\hline & $\begin{array}{l}\text { Synthesised } \\
\text { Finding }\end{array}$ & $\begin{array}{l}\text { Type of } \\
\text { Research }\end{array}$ & Dependability & Comments & Credibility & Comments & $\begin{array}{l}\text { ConQual } \\
\text { Overall } \\
\text { Score }\end{array}$ \\
\hline 1 & $\begin{array}{l}\text { There is a } \\
\text { fear among } \\
\text { nurses of the } \\
\text { negative } \\
\text { consequence } \\
\text { s of reporting } \\
\text { from their co- } \\
\text { workers and } \\
\text { supervisors }\end{array}$ & Qualitative & $\downarrow-1$ & $\begin{array}{l}\text { The dependability } \\
\text { score moved } \\
\text { down one level } \\
\text { from "High" to } \\
\text { "Moderate" as the } \\
\text { influence of the } \\
\text { researcher was } \\
\text { not clearly } \\
\text { addressed in all } \\
\text { the included } \\
\text { studies. }\end{array}$ & $\downarrow-1$ & $\begin{array}{l}\text { The credibility } \\
\text { score was } \\
\text { downgraded one } \\
\text { as there was a } \\
\text { mix of credible } \\
\text { and unequivocal } \\
\text { findings included } \\
\text { in the two } \\
\text { categories } \\
\text { associated with } \\
\text { the first } \\
\text { synthesised } \\
\text { finding. } \\
14 \text { (U) }+2 \text { (C) }\end{array}$ & Moderate \\
\hline 2 & $\begin{array}{l}\text { There is a } \\
\text { lack of the } \\
\text { organisational } \\
\text { support } \\
\text { needed to } \\
\text { foster an } \\
\text { incident } \\
\text { reporting } \\
\text { milieu for } \\
\text { nurses }\end{array}$ & Qualitative & $\downarrow-1$ & $\begin{array}{l}\text { The dependability } \\
\text { score moved } \\
\text { down one level } \\
\text { from "High" to } \\
\text { "Moderate" as the } \\
\text { influence of the } \\
\text { researcher was } \\
\text { not clearly } \\
\text { addressed in all } \\
\text { the included } \\
\text { studies. }\end{array}$ & $\downarrow-1$ & $\begin{array}{l}\text { The credibility } \\
\text { score was } \\
\text { downgraded one } \\
\text { as there was a } \\
\text { mix of credible } \\
\text { and unequivocal } \\
\text { findings included } \\
\text { in the two } \\
\text { categories } \\
\text { associated with } \\
\text { the second } \\
\text { synthesised } \\
\text { finding. } \\
\mathbf{9}(\mathbf{U})+\mathbf{8}(\mathbf{C})\end{array}$ & Moderate \\
\hline 3 & $\begin{array}{l}\text { Some nurses } \\
\text { are not well } \\
\text { trained to } \\
\text { take part in } \\
\text { the incident } \\
\text { reporting } \\
\text { system }\end{array}$ & Qualitative & $\downarrow-1$ & $\begin{array}{l}\text { The dependability } \\
\text { score moved } \\
\text { down one level } \\
\text { from "High" to } \\
\text { "Moderate" as the } \\
\text { influence of the } \\
\text { researcher was } \\
\text { not clearly } \\
\text { addressed in all } \\
\text { the included } \\
\text { studies. }\end{array}$ & $\downarrow-1$ & $\begin{array}{l}\text { The credibility } \\
\text { score was also } \\
\text { downgraded one } \\
\text { as there was a } \\
\text { mix of credible } \\
\text { and unequivocal } \\
\text { findings included } \\
\text { in the two } \\
\text { categories } \\
\text { associated with } \\
\text { the third } \\
\text { synthesised } \\
\text { finding. } \\
\mathbf{5 ( U ) + 1} \text { (C) }\end{array}$ & Moderate \\
\hline
\end{tabular}




\begin{tabular}{|l|l|l|l|l|l|l|}
\hline $\begin{array}{l}\text { Nurses lack the } \\
\text { motivation } \\
\text { needed to } \\
\text { ensure their } \\
\text { active } \\
\text { participation in } \\
\text { the incident } \\
\text { reporting system }\end{array}$ & Qualitative & & $\begin{array}{l}\text { The dependability } \\
\text { score moved } \\
\text { down one level } \\
\text { from "High" to } \\
\text { "Moderate" as the } \\
\text { influence of the } \\
\text { researcher was } \\
\text { not clearly } \\
\text { addressed in all } \\
\text { the included } \\
\text { studies. }\end{array}$ & $\leftrightarrow-1$ & $\begin{array}{l}\text { No change in the } \\
\text { credibility score } \\
\text { since this } \\
\text { synthesised } \\
\text { finding contained } \\
\text { only unequivocal } \\
\text { findings. } \\
\mathbf{4} \text { (U) }\end{array}$ & Moderate \\
& & & & \\
\hline
\end{tabular}

"Dependability" established by assessing the studies in the review using a set of 5 critical appraisal questions. Ranking: findings remain unchanged: 4-5 'yes' responses $(\leftrightarrow)$, downgraded one level: 2-3 'yes' responses ( $\downarrow-1)$, downgraded two levels: 0-1 'yes' responses ( $\downarrow$ - 2) (Munn et al., 2014).

"Credibility" ranked by assessing the congruency between the author' s interpretation and the supporting data. Ranking: no change: only unequivocal findings $(\leftrightarrow)$, downgraded one level: mix of unequivocal and credible findings $(\downarrow-1)$, downgraded two levels: all credible findings $(\downarrow-2)$, downgraded three levels: mix of credible and unsupported findings $(\downarrow-3)$, downgraded four levels: unsupported findings ( $\downarrow$ - 4) (Munn et al., 2014). 


\section{Figures}

Figure 1: PRISMA Flow Diagram

Figure 2: Meta Aggregative Quantitative Review Overview Chart

\section{Funding}

The work was conducted without external funding. 